\title{
A 300-Year Typhoon Record in Taiwan and the Relationship with Solar Activity
}

\author{
Chih-wen Hung \\ Department of Geography, National Taiwan Normal University, Taipei, Taiwan
}

Received 12 October 2012, accepted 18 February 2013

\begin{abstract}
Previous studies have identified possible linkages between solar activity and tropical cyclone activity in the United States and Caribbean. This study used historical typhoon records dating back to the early 1700s, the Central Weather Bureau records (since 1897), and the JTWC (Joint Typhoon Warning Center) (since 1945) to investigate the relationship between solar activity and the number of typhoons in Taiwan. The results show that a negative relationship exists between solar activity and typhoon frequency in Taiwan at decadal time scales. Fewer typhoons occurred during the periods 1770 to 1790 and 1930 to 1960, with a higher number of typhoons occurring during 1810 to 1830 and 1870 to 1930 . A likely mechanism for the relationship is that more intense solar activity can warm the lower stratosphere and the upper troposphere through absorption of solar radiation by atmospheric ozone. This would decrease the convective available potential energy and reduce the frequency of typhoon occurrence. As a consequence, fewer typhoons form over the western North Pacific with fewer affecting Taiwan. The negative correlation between solar activity and the number of typhoons affecting Taiwan is important to understand changes in the frequency and behavior of typhoons resulting from climate change.
\end{abstract}

Key words: Typhoon, Taiwan, Sunspot, Solar activity, Cosmic rays

Citation: Hung, C. W., 2013: A 300-year typhoon record in Taiwan and the relationship with solar activity. Terr. Atmos. Ocean. Sci., 24, 737-743, doi: 10.3319/TAO.2013.02.18.01(A)

\section{INTRODUCTION}

There is good evidence that extraterrestrial phenomena such as cosmic rays and solar irradiance can be related to hurricane activitiy. For example, the connection between solar activity and the frequency of Atlantic tropical cyclones was first suggested by Cohen and Sweetser (1975). Connections between North Atlantic cyclonic activity and changes in cosmic ray intensity were identified by Kavlakov (2005) and Pérez-Peraza et al. (2008). These studies argued that the reduced solar activity would allow more cosmic rays to penetrate the Earth's atmosphere, increase cloudiness and therefore affect the behavior of hurricanes. Recently, additional studies have found possible linkages between solar activity and tropical cyclones in the United States/Caribbean (e.g., Elsner and Jagger 2008, Hodges and Elsner 2011). The mechanism put forth for these relationships is that the more intense solar activity resulting in a warming of the lower stratosphere and the upper troposphere via absorption

\footnotetext{
* Corresponding author

E-mail: hungchihwen@gmail.com;cwhung@ntnu.edu.tw
}

of solar radiation by atmospheric ozone. The warming decreases the convective available potential energy (CAPE) and limits the intensity of cyclones. As a consequence, fewer hurricanes form over the western North Atlantic Ocean and affect the United States and Caribbean during periods of higher solar activity. If this mechanism operates at the global scale, a similar connection between solar activity and tropical cyclones should be observed in other regions, especially the western North Pacific (WNP) where many typhoons form every year.

In Taiwan, typhoons are the largest weather-related disasters (e.g., Wu and Kuo 1999). Typhoons contribute a large portion of the annual rainfall, and cause floods which can result in severe damage. On average, about $43.2 \%$ of the summer-to-fall rainfall is related to typhoons (Hung and Hsu 2010). The historical typhoon tracks in 1945 - 2010 provided by the JTWC (Joint Typhoon Warning Center) and shown in Fig. 1 indicate that Taiwan, Philippines, and Okinawa are located on the major typhoon routes over the WNP. Among these, Taiwan is located in the central area and is an ideal location to study trends in typhoon activity. 


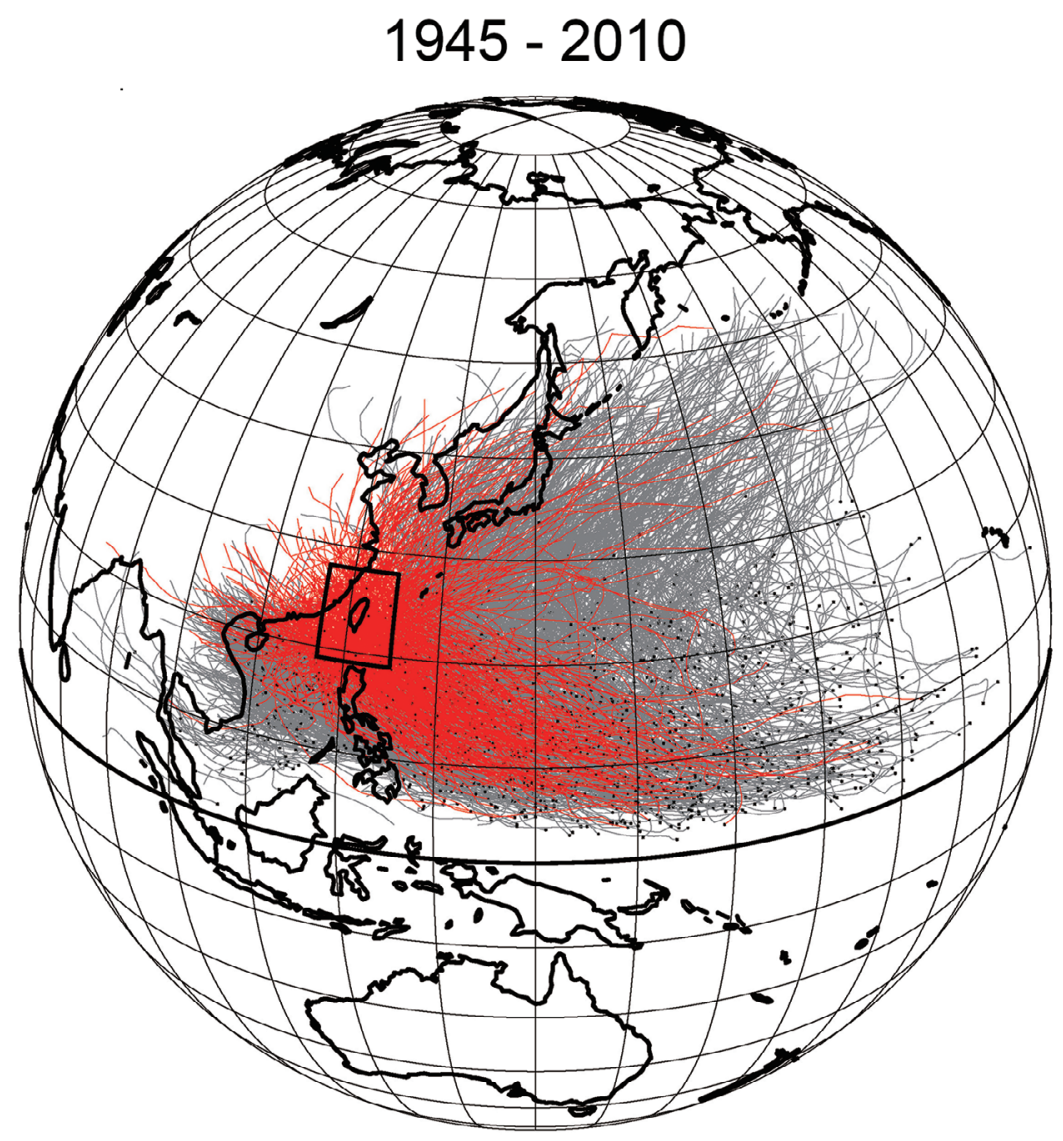

Fig. 1. JTWC typhoon tracks in the western North Pacific for $1945-2010$. The gray lines indicate the typhoon tracks and the red lines indicate the tracks for typhoons which moved through the study area $\left(19-28^{\circ} \mathrm{N}, 117-125^{\circ} \mathrm{E}\right.$, shown as the box).

Understanding variations in typhoon activity has become more important as related to climate change and predicting the resulting effects (Tu et al. 2009). The role of solar activity in modulating typhoon formation or behavior remains unclear. In this study, three different typhoon records in Taiwan were analyzed to examine the temporal trends in typhoon occurrence since the early 1700 s. Using this $300-$ year record, typhoon activity in Taiwan and the possible relationships with solar activity (represented by the number of sunspots on a decadal time scale) was investigated.

The rest of this paper is arranged as following. Section 2 describes how to construct the 300-year typhoon records in Taiwan from historical books and the modern typhoon records. Section 3 discusses the relation between the typhoon activity and the solar cycle. Finally, the conclusions are in section 4 .

\section{THE 300-YEAR RECORD OF TYPHOONS IN TAIWAN}

The Chinese character “tai” (颱, meaning typhoon) probably appeared in Chinese literature as early as the late $17^{\text {th }}$ century. Chou (1992) concluded that "tai" was actu- ally derived from another Chinese word "chu” (風), which was first seen in the 8th century. "Chu-feng" (風風) is still a term used in modern Chinese to indicate "hurricane" in English. Essentially, "chu" and "tai" refer to the same thing, but according to Chou (1992), it was about 900 years later when the Chinese character "tai" appeared following the use of "chu."

Two old books about Taiwan published at that time clearly contain "tai" in the text. These two books are: (1) “Tai-Wan-Chi-Ruei” (臺灣紀略 or “A Brief Summary of Taiwan"), published in 1685, and (2) "Tai-Wan-Fu-Chih" ( 臺灣府志 or “An Introduction to Taiwan Fu”), published in 1694. The latter was discussed by Ootani (1940) and Arakawa (1941). Based on the references mentioned above, it is clear that the Chinese character "tai" was used as early as the late 17th century in Taiwan and many historical records of typhoons can be found after 1700 . The Chinese character "tai" appearing in these books can provide many early records of the number of typhoon occurrences for scientific study today. Chen (1981) used detailed typhoon records from 1691 to 1894 (from Emperor Kang-shi to Emperor Kwang-hshi in the Ching dynasty) to document observations of typhoons in Taiwan based on Tsao (1963). The ty- 
phoon records listed by Tsao (1963) were collected from 47 books published in Taiwan during the Ching dynasty. These sources provide a valuable historic record of temporal variation in typhoon activity which can be used together with modern data to provide a long term record of typhoons.

Modern weather observatories in Taiwan were first introduced in 1896 - 1897 during the early Japanese colonial era. By January 1897 , there were five weather observatories operating in Taiwan (Hung 2007). The 1897 typhoon season was the first season for Taiwanese to collect modern scientific records of typhoons. The typhoon map for the No. 1 typhoon (August $9^{\text {th }}, 1897$ ) in Taiwan is shown in Fig. 2. This old typhoon map was acquired from an early report, Taiwan Meteorological Report No. 1 published by the Taihoku (Taipei) Weather Observatory of Taiwan Governor-General's Office in 1899 . This typhoon induced a very strong southwesterly monsoonal flow and caused serious flooding in the Taipei area. The railway bridge over the Tamsui River operated by the first Taiwan railway between Keelung and Hsinchu was totally destroyed by the flood.

The uncertainties in older historical records are important considerations for long-term climate studies. Because there are no other scientific observations of typhoons during the early period of Taiwan, historical and personal records are the only sources available. In the present study, these typhoon records were compared with an independent source, the personal diary written by George Leslie Mackay (1844 - 1901) between 1871 and 1894. The diary includes observations of 19 typhoons from the historical typhoon records. This seems to suggest that the typhoon records in the historical data set are reasonably accurate. There are another 15 typhoons listed in the historical dataset which were not mentioned by Mackay. The reasons for this difference are: (1) 2 typhoons occurred when entries in Mackey's diary are missing (1883), (2) 5 typhoons occurred when Mackay traveled abroad, and (3) 8 typhoons listed in the historical dataset affected southern Taiwan or the Peng-hu islands, while Mackay stayed in Tamsui, his home in northern Taiwan. Based on this comparison, the historical typhoon records from the Ching dynasty in Taiwan should be reliable for study.

Beginning in 1897, modern weather observatories were part of the Taiwan Governor-General's Office until the end of the World War II. After 1945, the Central Weather Bureau (CWB) collects more detailed observations of typhoons in Taiwan every year. The first complete typhoon records were published by the CWB in 1973 which covered 80-year typhoon tracks for 1892 - 1971. This record contains some inhomogeneities from the early period prior to 1910 due to unknown reasons. The CWB published a second typhoon record book "Tropical Cyclone Tracks over Taiwan and Its Vicinity 1897 - 1996" in 1998 (Xie et al. 1998). This book has four parts. Part I and Part II includes typhoons affecting Taiwan during the Japanese colonial era through the early post-war period (1897 - 1948) and the modern CWB period (1949 - 1996), respectively. The periods covered in Part III and Part IV are similar to that in Part I and Part II, but for typhoons not directly making landfall in Taiwan. In its abstract, the authors clearly indicate that the data in Part I and Part III are mostly from the records collected by the Taiwan Governor-General's Office. Part II and Part IV contain more detailed information provided by the JTWC (Xie et al. 1998). Therefore, the data quality in this 100-year typhoon record is actually divided into two major periods, before 1948 and after 1949.

In the present study, the number of typhoons affecting Taiwan was counted using the typhoon tracks passing through the area shown in Fig. $1\left(19-28^{\circ} \mathrm{N}, 117-125^{\circ} \mathrm{E}\right.$, defined in Hung and Hsu 2010). The JTWC data tends to include more typhoons than that in the CWB data, because the CWB changed the definition of "typhoon affecting Taiwan" from a scientific threshold to the loss of human lives and property after 1962 (CWB 1994). This change created an inhomogeneity in the CWB typhoon records. Therefore, the JTWC best track records are used after 1945 to avoid the inhomogeneity in the CWB data. Despite this change in definition, the typhoon records during the Japanese colonial era in the 100-year CWB record (Xie et al. 1998) are
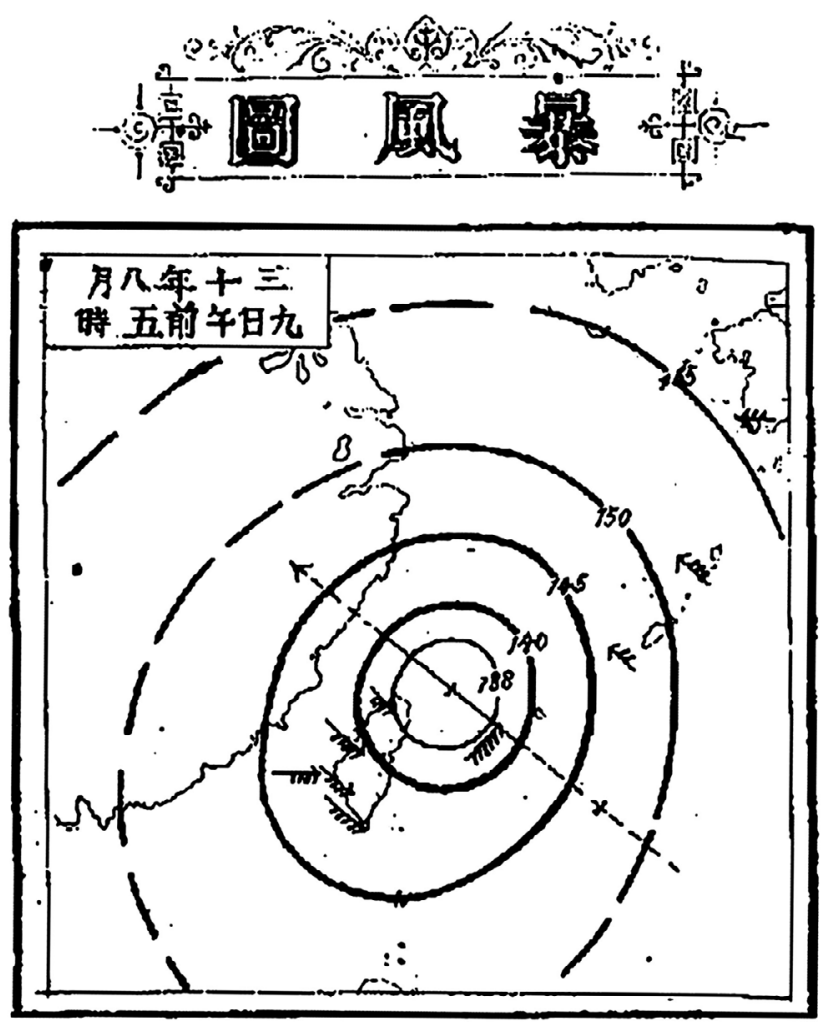

Fig. 2. The No. 1 typhoon (August $9^{\text {th }}, 1897$ ) in the modern scientific records for Taiwan. This map was acquired from the Taiwan Meteorological Report No. 1 published by the Taihoku (Taipei) Weather Observatory, Taiwan Governor-General's Office in 1899. 
necessary to fill the gap between the Ching dynasty records and the JTWC dataset.

To construct a 300-year record of typhoon affecting Taiwan, three different data sources were combined into one time series with the following considerations. The typhoon records from the Ching dynasty documented by Tsao (1963) and Chen (1981) from 1700 to 1894 were counted year by year. The CWB records including the official documents by the Taiwan Governor-General's Office from 1897 to 1944 were used for data collected during the Japanese colonial era, although the CWB data from Xie et al. 1998 includes the 100-year record from 1897 to 1996 . The best track data from the JTWC record was used for the period from 1945 to the present. Except the typhoon records from the Ching dynasty (Tsao 1963 and Chen 1981), the number of typhoons affecting Taiwan was counted by tabulating the number of typhoons entering the area as shown in the box in Fig. 1. The typhoon records from the Ching dynasty have a lower typhoon count, while the JTWC best track data contain a higher number of typhoon observations. This is due to the lack of modern technology from radar and satellite observations in the pre-World War II era. Fewer total numbers of typhoons are expected in the records compared to the number of typhoons after the war. For this reason, three different levels of data quality (Ching dynasty records, CWB records, and JTWC records) were considered. Although the observations in the time series are joined, a separate analysis was carried out for each record.

In order to use the 300-year typhoon observations in
Taiwan to represent WNP typhoon activities, the JTWC data is used to verify the conceptual approach. The ratio of the annual number of typhoons affecting Taiwan (defined as in Fig. 1) to the annual number of typhoons over the WNP is calculated. The annual ratio and the 11-year running mean are shown in Fig 3a. In addition, the 10-year accumulated ratio for the number of typhoons is shown in Fig. 3b. Although the ratio shows some interannual variation, the 11year running mean and the 10-year accumulated ratio have much less variation. The 10 -year accumulated ratios are about 0.25 for $1950-2000$, except during the recent decade after 2000 .

To analyze the interdecadal variation in the number of typhoons and the relationship to solar activity, the annual typhoon anomaly was calculated by subtracting the mean annual number of typhoons (red lines in Fig. 4a). The data for the number of sunspots for 1700 to 2010 are available from the Solar Influences Data Analysis Center (SIDC), World Data Center for the Sunspot Index, at the Royal Observatory of Belgium and is shown in Fig. 4b. The typhoon anomalies in Fig. 4a and the sunspot activity in Fig. 4b are smoothed with an 11-year running mean (Figs. 4c and d), based on the 11-year sunspot cycle identified by Heinrich Schwabe in 1843 . To avoid creating spurious time series at the boundaries due to the data quality, a separate calculation for each of the running means for each of the three periods was used and a reflective (symmetric) condition is set to avoid the missing data at the boundaries of each time series.

(a)

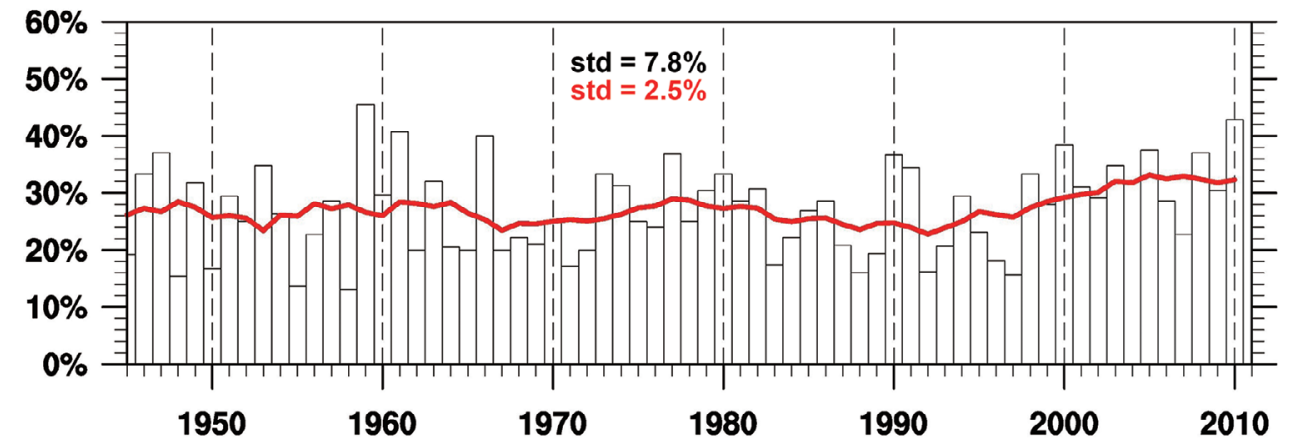

(b)

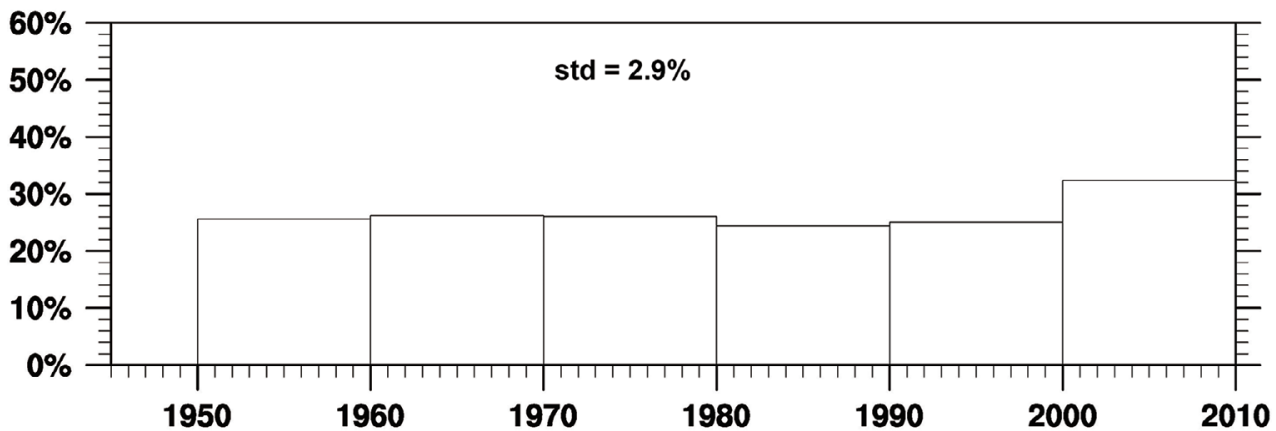

Fig. 3. The ratio of the number of typhoons affecting Taiwan to the total number of typhoons over the WNP. (a) The yearly values and the 11-year running means are shown as a bar and red line, respectively. (b) The 10-year accumulated ratio for (a). "std" refers to the standard deviations for the ratio. 
(a)

(b)

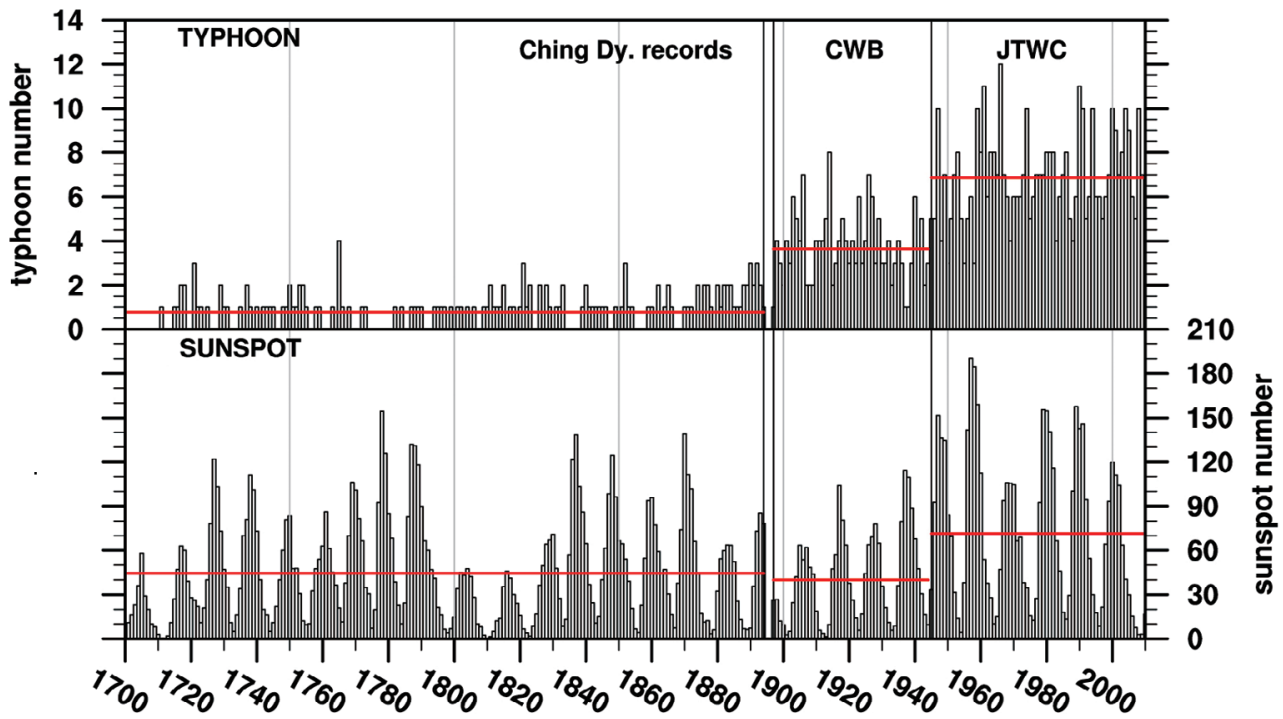

(c)

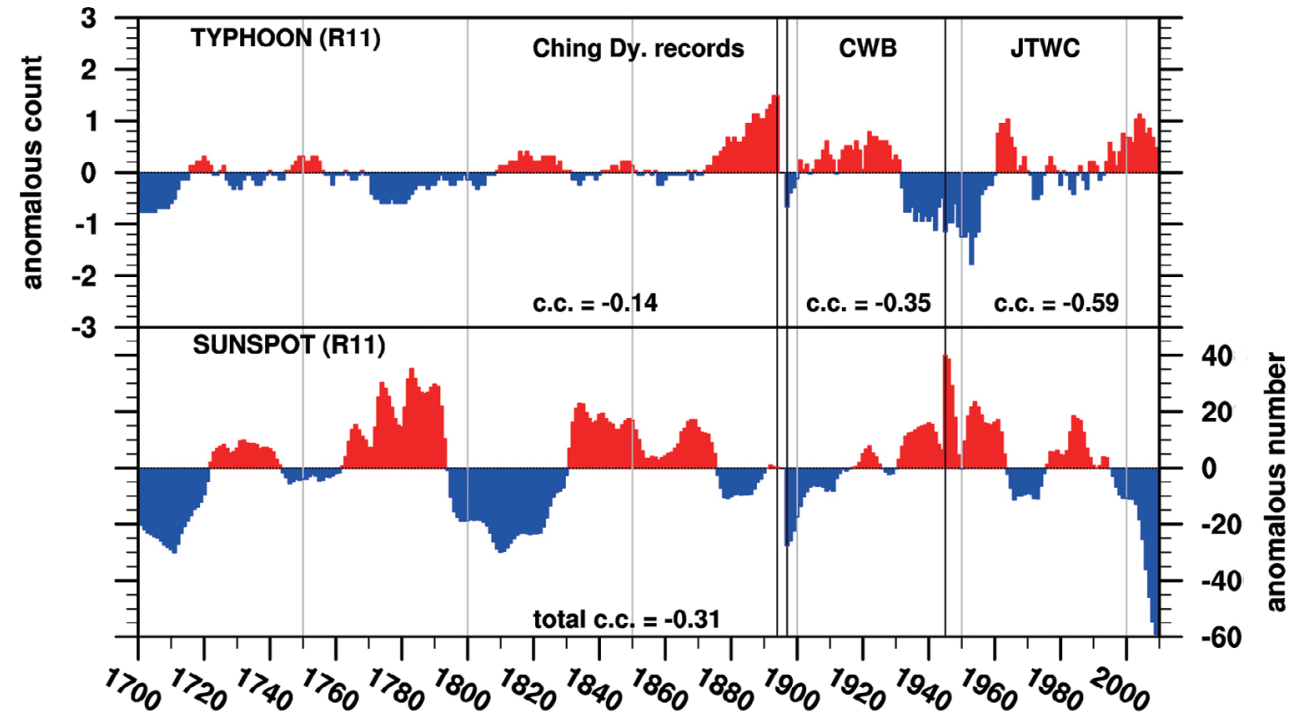

(e)

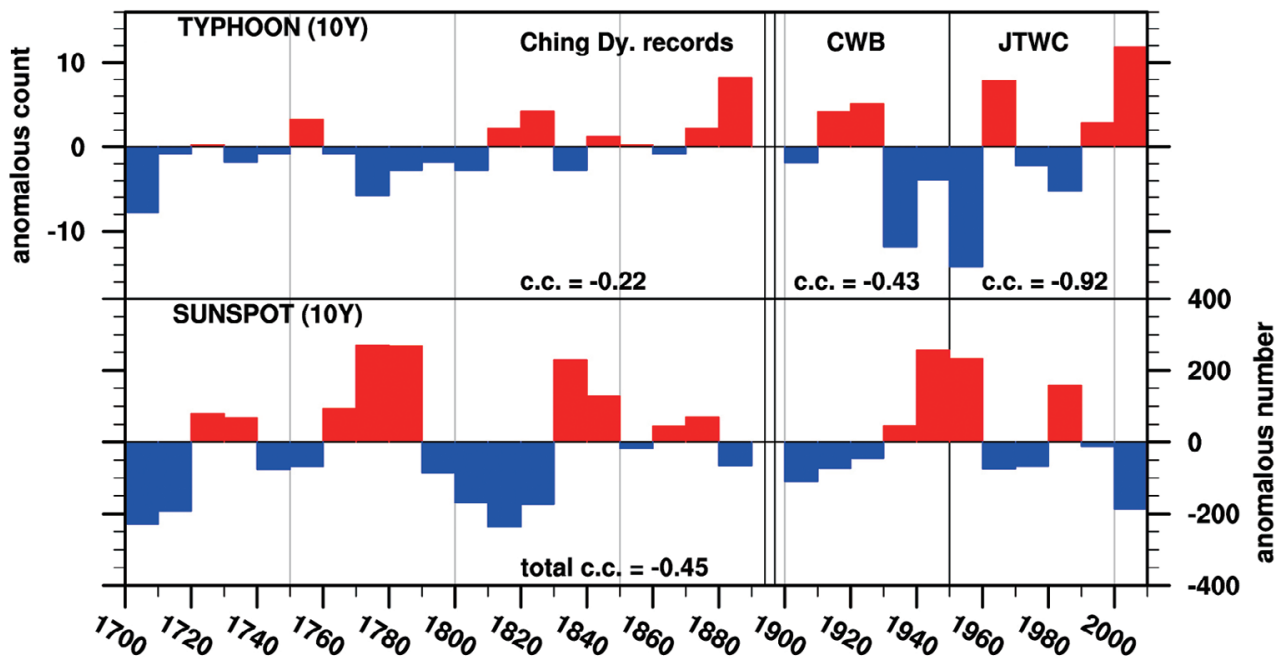

Fig. 4. Annual values for (a) the number of typhoons in Taiwan and (b) sunspot activity. (c) and (d) are similar to (a) and (b) but for the 11-year running mean anomaly for (a) and (b), respectively. (e) and (f) are similar to (c) and (d) but for the decadal (10-year) accumulated anomaly values for (a) and (b), respectively. The anomaly for the sunspot numbers is calculated based on the red lines in (a) and (b). In the typhoon records (a), (c), and (e), the 300-year data are divided into three different periods indicated by (1) Ching dynasty records, (2) CWB records, and (3) JTWC records. " $r$ " represents the correlation coefficients for each period in (c) and (e). The "total $r$ " in (d) and (f) indicates the correlation coefficients for the entire period. The missing data in (c) - (f) is due to a lack of records for 1895 - 1896. 


\section{RESULTS AND DISCUSSION}

The correlation coefficient (r) between the number of typhoons and the number of sunspots for the period 1700 to 2010 is $-0.31(r=-0.14,-0.35$, and -0.59 for the three data sets, respectively, as indicated in Fig. 4c). In addition, using the data shown in Figs. 4a and b, the 10-year accumulated values are shown in Figs. 4e and f. The 10-year accumulated values represent the sum for each decade, and $r=-0.45$ $(r=-0.22,-0.43$, and -0.92 , for the three data sets, respectively, as indicated in Fig. 4e). The correlation coefficients for 11-year running mean and the decadal accumulated values are -0.31 and -0.45 , indicating the negative relationship between the number of typhoons and the sunspot activity. Although the correlation does not imply causation, a linkage between the number of typhoons and solar activity is plausible because the likely mechanism (warming via absorption by atmospheric ozone) is consistent with the inverse relationship.

The relationship is clearly seen using a decadal time scale (11-year running mean or 10-year accumulated values), but not at shorter (such as annual) time scale. This is because the ratio of number of typhoons affecting Taiwan to the total number of typhoons in the WNP varies due to the interannual variability in the air-sea interactions and many other factors over the Pacific Ocean. Using the decadal calculation or the similar 11-year running mean, the interannual variation in the ratio is reduced and a clearer long-term connection between the number of typhoons and solar activity can be seen (Fig. 3). The 300-year typhoon record for Taiwan can be representative of the typhoons over the WNP only when the interannual variation is reduced.

A negative relationship between solar activity and the number of hurricanes affecting the United States and Caribbean was identified by Elsner and Jagger (2008). A similar negative correlation occurs for the WNP using the 300-year typhoon record in Taiwan (Fig. 4). Fewer typhoons affect Taiwan during periods with higher solar activity on a decadal time scale. The lower number of typhoons in 1770 1790 and 1930 - 1960, and a higher number of typhoons in $1810-1830$ and $1870-1930$ is associated with more active and less active solar activity, respectively. It is likely that the mechanism suggested by Elsner and Jagger (2008) where higher solar activity warms the lower stratosphere and the upper troposphere via absorption of solar radiation by atmospheric ozone also operates over the WNP. The result is a decrease in the convective available potential energy (CAPE), which reduces the intensity of cyclonic storm systems. As a consequence, fewer typhoons form over the WNP and affect Taiwan. During periods with decreased solar activity, the opposite pattern is observed, resulting in an increase in the number of typhoons.

Even though the linkage between solar activity and the number of typhoons in the WNP seems clear, various mechanisms probably contribute to the relationship. For example, solar activity might impact large-scale atmospheric circulation and the Pacific subtropical high. Since the typhoon steering flow associated with subtropical high is a determinant of typhoon tracks, the number of typhoons affecting Taiwan might also be related to changes in the position of it. However, the number of typhoons observed in any place in the WNP basin is related to both of the total number of typhoons over the WNP and any changes in the steering flow associated with the Pacific subtropical high. Therefore, decadal variation in large-scale atmospheric circulation might result from multiple mechanisms. Changes in ocean currents, air-sea interaction or climate change can contribute to variation in atmospheric circulation. One way to further document the relationship between the number of typhoons and solar activity would be to count the total number of typhoons occurring basin-wide in the WNP. However, it may not be possible to obtain such typhoon records for the time period before 1945. This is why the current study used the number of typhoons affecting Taiwan to represent the typhoon activity in the WNP. Because the ratio of the number of typhoons affecting Taiwan to the total number of typhoons in the WNP is quite stable on the decadal time scale, except the decade following the year 2000 (see Fig. 3), the decadal number of typhoons in Taiwan is used to represent the typhoon activity basin-wide here.

\section{CONCLUSIONS}

In this study, long typhoon records back to early 1700 s from the old historical archives in the Ching dynasty, the Central Weather Bureau records (from 1897) and the JTWC data (from 1945) were used to construct a 300-year record of the number of typhoons affecting Taiwan. A large dataset of the sunspot number for the period 1700 to 2010 available from the Solar Influences Data Analysis Center (SIDC) was used to examine the relationship between solar activity and the number of typhoons. The unique 300-year record of the number of typhoons and solar activity shows that on a decadal time scale, a negative relationship exists between solar activity and typhoon frequency in Taiwan. Fewer typhoons occurred during the periods 1770 to 1790 and 1930 to 1960, with a higher number of typhoons occurring in 1810 to 1830 and 1870 to 1930 . Previously, a negative correlation between typhoon activity over the Atlantic Ocean and solar activity was identified. The results of this study show that the relationship between solar activity and the number of typhoons over the WNP is similar. This finding is important when discussing typhoon activities under the climate change, especially a possible upcoming solar minimum after the current Modern Maximum. This decadal variation is also very important for people in Taiwan to carefully monitor to prevent the typhoon disaster in the future decades. 
Acknowledgements The author would like to dedicate this work to the late Prof. Michio Yanai at UCLA for his patience and enthusiastic encouragement on this typhoon study, and the late Prof. Katsuyoshi Shiratori at Taihoku Imperial University for his pioneering work of the cosmic rays in Taiwan. Special thanks are extended to Prof. Kuoyen Chen for his inspiration of this work, and Mr. Y. M. Li and Mr. H. J. Lin for their help in figure preparation. This work was supported under Grant NSC 99-2111-M-003001-MY3, NSC 102-2621-M-492 -001 and MOTC-CWB101-M-02.

\section{REFERENCES}

Arakawa, H., 1941: History of Japanese Meteorology, Awade-Shobo, Tokyo, 191 pp. (in Japanese)

Chen, K. Y, 1981: On typhoon disasters in Taiwan during the period of Ching dynasty. J. Natl. Taiwan Norm. Univ., 26, 381-398. (in Chinese)

Chou, M. D., 1992: The Wind and Rain in Taiwan - The Meteorological Proverb and History of Taiwan, LiangMing Publishing Co., Taipei, 172 pp. (in Chinese)

Cohen, T. J. and E. I. Sweetser, 1975: The 'spectra' of the solar cycle and of data for Atlantic tropical cyclones. Nature, 256, 295-296, doi: 10.1038/256295a0. [Link]

CWB (Central Weather Bureau), 1994: Summary of Typhoon Warnings Issued by the Central Weather Bureau in 1958 - 1993, Central Weather Bureau, 81 pp. (in Chinese)

Elsner, J. B. and T. H. Jagger, 2008: United States and Caribbean tropical cyclone activity related to the solar cycle. Geophys. Res. Lett., 35, L18705, doi: 10.10 29/2008GL034431. [Link]

Hodges, R. E. and J. B. Elsner, 2011: Evidence linking solar variability with US hurricanes. Int. J. Climatol., 31, 1897-1907, doi: 10.1002/joc.2196. [Link]

Hung, C. W., 2007: The History of Meteorological Observatories in Taiwan, Taiwan Interminds Publishing Inc.,
Taipei, 296 pp. (in Chinese)

Hung, C. W. and H. H. Hsu, 2010: Contribution of typhoons to the rainfall in Taiwan. $14^{\text {th }}$ International Conference on Geography in Taiwan, NTNU, Taipei, Taiwan, May 22-23, 2010.

Kavlakov, S. P., 2005: Cosmic ray changes and total North Atlantic cyclonic activities. Proceedings of the $29^{\text {th }}$ International Cosmic Ray Conference, August 3 - 10, 2005, Pune, India, vol. 2, 295-298.

Ootani, T., 1940: Bo Fu U (Violent Wind and Rain), Iwanami-Shinsho, Tokyo, 158 pp. (in Japanese)

Pérez-Peraza, J., V. Velasco, S. Kavlakov, A. GallegosCruz, E. Azpra-Romero, O. Delgado-Delgado, and F. Villicaña-Cruz, 2008: On the trend of Atlantic hurricane with cosmic rays. Proceedings of the $30^{\text {th }}$ International Cosmic Ray Conference, July 3 - 11, 2007, Mérida, Yucatán, Mexico, vol. 1, 785-788.

Taipei Weather Observatory of Taiwan Governor-General's Office, 1899: Taiwan Weather Report I, Taipei Weather Observatory of Taiwanese Governor-General Office, Taipei, 58 pp. (in Japanese)

Tsao, Y. H., 1963: The history of floods in Taiwan. In: The History Collection of Economy in Taiwan IX, Research Room for Economy of Taiwan Bank Taipei, 16-55. (in Chinese)

Tu, J. Y., C. Chou, and P. S. Chu, 2009: The abrupt shift of typhoon activity in the vicinity of Taiwan and its association with western North Pacific-East Asian climate change. J. Climate, 22, 3617-3628, doi: 10.1175/ 2009JCLI2411.1. [Link]

Wu, C. C. and Y. H. Kuo, 1999: Typhoons affecting Taiwan: Current understanding and future challenges. Bull.Amer. Meteorol.Soc., 80, 67-80, doi: 10.1175/15 20-0477(1999)080<0067:TATCUA > 2.0.CO;2. [Link]

Xie, X. L., S. D. Wang, M. D. Zheng, and T. J. Ye, 1998: Tropical cyclone tracks over Taiwan and its vicinity 1897-1996. Central Weather Bureau, Taipei. (in Chinese) 